\section{Las porcelanas del Buen Retiro}

\author{
C. Mañueco, M. Granados. Museo Arqueológico Nacional
}

S. Quero Museo Municipal de Madrid

P. Mena, F. J. Marín, G. Yañez Dirección General del Patrimonio Histórico Artístico de la C.A.M

M. Becerril, A. López Alonso, L. Cuarta Escuela de Cerámica de la Moncloa

M. Regueiro, L. Cespedes. Instituto Tecnológico Geominero de España

J. M⿻ Rincón, M⿻ $\mathbf{a}$ S. Hernández Instituto Ciencias de la Construcción y del Cemento Eduardo Torroja. CSIC

S. de Aza, E. Criado, R. Martínez, F. J. Valle, J.Mª Fernández Navarro. Instituto de Cerámica y Vidrio CSIC (Coordinación del Proyecto):

\begin{abstract}
Memoria Proyecto de Investigación de la Comunidad de Madrid.
Conserjería de Educación. Dirección Gral. de Investigación

Dada la difusión alcanzada en la prensa nacional e internacional por las noticias relativas a los trabajos en curso sobre las Porcelanas del Buen Retiro, se ofrece a continuación un amplio resumen de la memoria redactada por el equipo de investigación a quien la Conserjería de Educación de la Comunidad de Madrid encomendó la realización del Proyecto PORCELANAS DEL BUEN RETIRO.
\end{abstract}

\section{Antecedentes Históricos}

A lo largo del siglo XVIII, las principales cortes Europeas desarrollan manufacturas cerámicas, dentro de un proceso genérico de fortalecimiento de las Fábricas Reales, al cuál no fue ajeno el Reino de España. La creación de la Real Fábrica de Porcelanas del Buen Retiro se inserta en este marco, y su estudio debe ser concebido en relación con el patronato regio y el influjo de la ilustración española de la centuria

La introducción en Europa de la Porcelana China ( porcelana dura), constituyó una de las etapas clave de la industrialización y supuso, en su momento, un esfuerzo de integración de conocimientos científicos y técnicos, recursos económicos y organizativos sin precedentes. En los trabajos de investigación se involucraron los científicos más prestigiosos y la lucha por obtener el denominado oro blanco constituyó un elemento de prestigio y de competencia económica entre las diferentes cortes ilustradas europeas ( Alemania. Francia, Inglaterra, España, etc.) las cuales soportaron económicamente su progreso. Sería finalmente en Meissen (Alemania ) en 1715 y bajo el patrocinio de Augusto el fuerte, Elector de Sajonia y Rey de Polonia, cuando J.F. Böttger, obtiene la primera porcelana europea. A lo largo del siglo su secreto, con las adaptaciones locales oportunas, se extendería al conjunto de los países europeos

En este contexto la actividad de la Real Fábrica del Buen Retiro, conocida popularmente como la Fábrica de la China, que se desarrolla entre 1759 y 1808, estuvo marcada por una serie de circunstancias que condicionaron su evolución. Su creación , por Carlos III es tardía respecto al resto de manufacturas europeas; su dependencia de la Manufactura Napolitana de Capodimonte (operarios, materias primas, técnica productivas, etc.) es significativa; por otro lado, ser la única manufactura española dedicada exclusivamente a la producción de porcelana, la privó del cualquier intercambio de influencias con empresas semejantes, etc. En otro orden de cosas, el precipitado e inesperado final del Buen Retiro como consecuencia de la guerra de la Independencia, ocasionó entre otros desastres, la pérdida de la mayor parte de la documentación, envolviendo su historia en una densa nebulosa, sólo alumbrada por algunas aportaciones aisladas. El arrasamiento final de la fábrica, bajo el reinado de Fernando VII, eliminó finalmente casi cualquier vestigio físico de la instalación

\section{Equipo de Investigación. Objetivos y Estructura del Proyecto}

Desentrañar y hacer aflorar los condicionamientos técnicos, económicos y el entorno histórico en que se desarrollo la actividad productiva de la Fábrica de Porcelanas del Buen Retiro, requería la puesta en marcha de un equipo multidisciplinar. Así lo entendió la Conserjería de Educación de la Comunidad de Madrid que, a través de la Dirección General de Investigación de la CAM, convocó a un grupo de trabajo que ha estado constituido por las siguientes instituciones y personas:

Museo Arqueológico Nacional: Carmen Mañueco, Marian Granados.

Museo Municipal de Madrid: Salvador Quero

Dirección General del Patrimonio Histórico Artístico de la C.A.M: Pilar Mena, Francisco J. Marín, Gregorio Yañez

Escuela de Cerámica de la Moncloa: Margarita Becerril, Alvaro López Alonso, Luis Cuarta

Instituto Tecnológico Geominero de España: Manuel Regueiro, Laura Cespedes.

Instituto Ciencias de la Construcción y del Cemento Eduardo Torroja. CSIC: Jesús Mํㅡㄹ Rincón, Mª Sol Hernández

Instituto de Cerámica y Vidrio CSIC (Coordinador del Proyecto): S. de Aza, E. Criado, R. Martínez, F. J. Valle, J.Ma Fernández Navarro.

El proyecto, desarrollado a lo largo del 2000, ha incluido las siguientes etapas:

- Recopilación de la bibliografía existente desde el punto de vista histórico, artístico, museístico y arquitectónico

- Investigación de la localización de los yacimientos de materias primas utilizados en la fabricación

- Clasificación de los fragmentos de porcelanas y lozas procedentes de excavaciones arqueológicas 
- Caracterización física, química mineralógica y microestructural de las piezas procedentes de los fondos arqueológicos y museísticos

- Determinación de los procesos productivos empleados en la Fabrica.

- Reproducción de las pastas cerámicas y ciclos térmicos utilizadas en la Fábrica

\section{RESULTADOS}

Los estudios se han centrado en la etapa final de la Fábrica del Buen Retiro, a partir de 1804, en que estuvo, bajo la dirección de Bartolomé Sureda. Este prototipo del técnico ilustrado, había adquirido un sólido conocimiento de las técnicas textiles en Inglaterra (1793-1796) y bajo el influjo de Agustín de Bethencourt, máxima figura de esa generación, es encargado por el Rey Carlos IV de poner en marcha una reorganización total de la fábrica, tras los repetidos fracasos técnicos y económicos que habían impedido la obtención de una verdadera porcelana. Su actuación abarcará todo el ciclo fabril: desde las materias primas a los procesos productivos, pasando por la propia gestión económica.

La sistematización en el uso de materias primas y en particular el recurso a una materia prima magnesítica muy abundante en las cercanías de Madrid, le permitieron obtener una pasta de gran calidad utilizable también en vajillas, capaz de soportar los cambios térmicos asociados a su uso con líquidos calientes, superando así uno de los grande obstáculos de las producciones anteriores.

\subsection{Arqueología-Museística}

Los estudios que han venido desarrollando el equipo de arqueólogos de la D. Gral. de Patrimonio de la CAM, han permitido localizar, en la zona conocida como Huerto del Francés del Retiro, los basamentos de la Ermita de San Antonio sobre la que se construyó la Real Fábrica, así como delimitar la red de desagüe perimetral que rodeaba la fábrica y que acababa en un largo túnel hacia el arroyo del Prado. En la alberca situada en dicha zona, que ha sido objeto de restauración, se han recuperado una gran cantidad fragmentos cerámicos. Dichos fragmentos incluyen restos de materias primas, pruebas de pastas, restos desechos de fabricación, fundamentalmente de vajillería. Los fragmentos fueron examinados por el equipo del Museo Arqueológico Nacional, que seleccionaron aquellos que podrían incluirse tipológicamnte como procedentes de la época Sureda

\subsection{Estudios químicos, físicos, mineralógicos y microestructurales}

Los estudios químicos, físicos, mineralógicos y microestructurales efectuados por los investigadores de los Institutos de Cerámica y Vidrio y el de Ciencias de la Construcción del CSIC han constatado, sin duda alguna, el empleo de materias primas de origen magnesítico. Dichos análisis han confirmado por primera vez, con datos experimentales, el empleo de la sepiolita como materia prima suministradora del magnesio, cuyo empleo es lo que caracteriza y diferencia a las producciones de Sureda del resto de las producciones europeas de porcelanas y que permite hablar propiamente de "porcelanas de Madrid".

Los resultados analíticos obtenidos, sobre tres muestras claramente definidas tipológicamente como de la época de Sureda, muestran una gran reproducibilidad. Las composiciones químicas registran valores de $\mathrm{MgO}$ entre $8.9 \%$, y $10.6 \% ; \mathrm{Al}_{2} \mathrm{O}_{3}$ de $8.7 \%$ a $10.1 \% ; \mathrm{SiO}_{2}$ de 77.3 a $76.2 \%$ y contenidos en alcalinos entre $1.5 \%$ y 2,0\%. El estudio microestructural corroboró la presencia de cuatro componentes mineralógicos diferentes: una matriz vítrea continua, $\alpha$-cuarzo muy finamente molido (por debajo de $10 \mu \mathrm{m}$ ) y unos aglomerados cristalinos constituidos por protoenstatita y $\alpha$-cristobalita, cuya composición mineralógica y química se corresponde claramente con la correspondiente a la transformación a alta temperatura $\left(\sim 1250^{\circ} \mathrm{C}\right.$ a $\left.\sim 1300^{\circ} \mathrm{C}\right)$ de la sepiolita de Vallecas, actualmente en explotación por la compañía Tolsa. Estos datos analíticos diferencian claramente la producción de Sureda, de las pastas inglesas y francesas de la misma época en cuya composición se emplearon también componentes conteniendo óxidos de magnesio, pero utilizando como materia prima ciertas "saponitas" acompañadas siempre de adiciones de PbO.

$\mathrm{El}$ análisis de otros restos encontrados confirman también el elevado grado de experimentación desarrollado a lo largo de la vida de la factoría. Así ha sido posible encontrar muestras, marcadas claramente como Buen Retiro y correspondientes a la primera época de la fábrica, con composiciones químicas muy cercanas a una porcelana triaxial dura convencional, con una constitución mineralógica con presencia de mullita, $\alpha$-cuarzo e indicios de $\alpha$-cristobalita y otras, que sin estar atribuidas previamente a época alguna, se puede asegurar que fueron ensayos en la época de Sureda, por estar constituidas fundamentalmente por: $\alpha$-cuarzo, $\alpha$-cristobalita, sulfato de bario y en menor cantidad casiterita y óxido de plomo.

\subsection{Materias primas}

Los estudios efectuados por el Instituto Tecnológico Geominero de España han permitido la localización de mas de 16 yacimientos, distribuidos por todo el país, cuyo empleo en la fábrica del Buen Retiro se menciona en la bibliografía existente. Revisten especial interés los yacimientos localizados en la propia provincia de Madrid: Colmenar Viejo, Galapagar, Valdemorillo, San Fernando, Cerro de Almodovar y Huerta de Zabala (camino de Vicálvaro, Madrid). El empleo de la sepiolita de estos últimos yacimientos es como ya se ha indicado una de las modificaciones y logros clave introducidos por Sureda. La información obtenida permite constatar lo exhaustivo y costoso de los trabajos destinados a garantizar el suministro y ensayo de todo tipo de materias rimas susceptibles de emplearse en la producción de porcelanas.

\subsection{Reproducción de las composiciones de las porcelanas}

Con la información y materias primas suministradas por el equipo del ITGE, la Escuela de Cerámica de la Moncloa ha reproducido cuatro tipos de pastas, cuya composición y propiedades se acercan a las observadas en las piezas procedentes de la excavación de la Fabrica del Buen Retiro y estudiadas por los grupos del ICV y del ICCET .

No obstante, los trabajos desarrollados hasta el momento no permiten encontrar un acuerdo concluyente entre las composiciones de las piezas de excavación y las teóricas calculadas a partir de las recetas descritas en la bibliografía encontrada, que des- 
criben las materias primas utilizadas en el Buen Retiro. Esta falta de acuerdo puede ser debida a:

- la utilización en la fabricación de las piezas procedentes de la excavación de una receta aún no encontrada,

- no haber sido identificados los materiales de partida utilizados para la fabricación,

- ser estos los yacimientos encontrados, los realmente utilizados, pero variar haber variado su composición durante el proceso de depuración y preparación de las pastas en fábrica.

Atendiendo a este último supuesto se procedió a los tratamientos de: separación granulométrica, lavados, procesos de envejecimiento y térmicos correspondientes siguiendo métodos de la época estudiados en la bibliografía relativa a las fábricas centroeuropeás.

La producción de pastas se ha reproducido a pequeña escala, de acuerdo con usos y utillaje de las fábricas de la época, siguiendo los pasos: preparación de las materias primas, preparación de la pasta de porcelana dura y configurado de piezas.

En la ensayística reproductora del método de producción se han usado materias primas autóctonas próximas a la fábrica: Galapagar, Colmenar Viejo y Cerro Alomodovar (Vallecas) y alejadas como La Coruña, Haro y La Roda.

Se han comparado con recetas de otras manufacturas, comprobándose que difieren bastante de las centroeruopeas.

En ausencia de datos arqueológicos sobre las instalaciones del proceso de producción especialmente los hornos de Buen Retiro, se lleva a cabo un estudio bibliográfico y documental de hornos y otros instrumentos concluyendo por aproximación en las curvas de hornada, lo que lleva a obtener piezas cocidas de la porcelana dura elaborada y seleccionada con los criterios antedichos.

Los métodos de ensayo utilizados han servido para comprobar que las propiedades de los materiales y productos obtenidos, son potencialmente equiparables a los que se obtuvieron en la Real Manufactura.

Interpretando y reproduciendo realmente estas recetas, se ha conseguido obtener un producto de calidad equivalente a la porcelana que fabricó Buen Retiro.

\subsection{Información Archivistica y Documental}

La información documental elaborada por el M.A.N. y los técnicos de la C.A.M., se ha sistematizado en dos bases de datos: una Bibliográfica y otra Iconográfica:

Bibliográfica:

El trabajo de los historiadores de la Dirección Gral. de Patrimonio del CAM, han permitido confirmar las fuentes de información disponible, en ausencia de los archivos propios de la Fábrica, destruidos en su inmensa mayoría.

Las fuentes básicas son:

a) Documentos del Patrimonio de la Corona. Archivo General de Palacio

Incluye los gastos relativos a la construcción de la fábrica, así como parcialmente al edifico destinado a residencia de oficiales y operarios. Se incluyen algunos expedientes personales de los operarios y oficiales, así como alguna anotación al capítulo de entrada y salida de géneros entre 1804 y 1806

b) Archivo General de Simancas. Sección de Hacienda.

En el se integran los documentos remitidos a Hacienda, para la fiscalización del presupuesto de la Real Fábrica. No se encuentran las series anuales completas, solamente los datos relativos a años aislados y un memorial elevado a Carlos IV sobre el lamentable estado en que se encontraba la fábrica a finales del XVIII

c) Dirección General del Tesoro

Incluye los datos relativos a presupuestos corrientes como lo tocante al nombramiento de empleados. Son datos que abarcan el período completo 1758-1808, pero en todo caso muy sintética

El análisis detallado de estas fuentes documentales es una tarea pendiente. Un análisis preliminar indica que no se encuentran completos todas las series históricas y que en otros casos la información es excesivamente sintética

Iconográfica

Se ha clasificado los fondos de vajillas correspondientes a la época Sureda, existentes en los Museos que tiene mayor número de piezas de esta época: Museo Arqueológico Nacional y Museo Municipal de Madrid. Una ficha tipo incluye la descripción, marcas, técnica de elaboración y decoración etc., junto a la fotografía y dibujo de la pieza.

Falta por analizar los fondos escultóricos, de gran importancia en la producción de la fábrica

\section{CONCLUSIONES PREVIAS}

El trabajo desarrollado permite aflorar un conjunto muy importante de información histórica y técnica, sobre la Fábrica de Porcelanas del Buen Retiro, permitiendo disponer de información sistematizada que ayude a cubrir la laguna de información existente. Esta falta de información global hace que la imagen y difusión internacional de la actividad de la Fábrica del Buen Retiro sea prácticamente inexistente o muy marginal e incompleta en la bibliografía internacional.

El proyecto, en combinación con los trabajos previos, ha permitido fijar la localización de la fábrica, sus dimensiones, costos y empleados, así como los datos básicos sobre la organización del trabajo y cuestiones administrativas. En su momento la fábrica fue una de las mayores instalaciones fabriles de Madrid, e innovadora en temas como relaciones laborales. Su personal, dado el patronazgo real, dispuso de unas condiciones de trabajo, remuneraciones, asistencia sanitaria, ayudas de jubilación, orfandad o viudedad inexistentes para los trabajadores de la época

La falta de información es especialmente relevante en lo relativo a los aspectos técnicos. materias primas, productos y procesos productivos. El trabajo desarrollado, permite concluir que en su etapa final, bajo la dirección de Sureda, la fábrica fue capaz de lograr una producción con características técnicas propias, basada en el empleo de una materia prima como la sepiolita, cuyos yacimientos de Madrid, son únicos en el mundo.

Su empleo permitió extender la producción a la vajillería, abriéndose así a un mercado potencial mucho mayor que el estrictamente suntuario que habría predominado en etapas previas. En todo caso sus pastas permitieron desarrollar también una importante obra plástica, así como la realización de pavimentos para residencias reales cuyos estudios están pendientes de abordarse. 